\title{
High occurrence of cyclosporiasis in Istanbul, Turkey, during a dry and warm summer
}

\author{
Melda Ozdamar', Elif Hakko² and Salih Turkoglü1,3
}

\begin{abstract}
We evaluated the incidence of Cyclospora cayetanensis in immunocompetent, diarrheic patients during the summers of 2006-2009 in Istanbul. Stools from 1876 patients were examined using microscopic techniques. Cyclospora oocysts were observed in wet preparations by light and epifluorescence microscopy and in fecal smears that were stained by Kinyoun's modified acid-fast stain. Characteristic Cyclospora oocysts were observed in 2 patients in 2006, 17 in 2007, and one in 2009. Samples positive for Cyclospora were further analyzed by a single step polymerase chain reaction (PCR) with Cyclospora-specific primers from the ITS-1 region of the genome.

The majority of the Cyclospora positive cases (15) were clustered during about 15 days in June 2007, indicating an unusual incidence of cyclosporiasis in this time period. The climatic characteristics of 2007 could have played a role in this high occurrence rate.
\end{abstract}

\section{Findings}

Cyclospora cayetanensis is a frequently reported emerging pathogen that causes diarrhea in humans. It was first described as causing prolonged, watery diarrhea in humans in Papua New Guinea by Ashford in 1979. The species designation Cyclospora cayetanensis was given in 1994 to Peruvian isolates of human-associated Cyclospora by Ortega and colleagues [1]. This pathogen is found worldwide but predominates in tropical and subtropical areas [2]. After ingestion and infection in the host, the parasites' unsporulated oocysts are excreted with the feces and must sporulate to be infectious. This requires 7 to 15 days under a certain temperature $\left(23\right.$ to $\left.27^{\circ} \mathrm{C}\right)$ and humidity [3]. Outbreaks of diarrheal disease in humans have been linked to the consumption of raspberries, salads, basil and Asian freshwater clams; have been reported in North, Central and South America, Asia, Africa, Australia, England, and Eastern Europe [3-9]. These outbreaks are usually associated with importation of contaminated food products or contaminated water sources [2,9]. Cyclospora cayetanensis is primarily regarded as a cause of traveler's diarrhea, and it is not usually included in the routine laboratory algorithms for immunocompetent patients, unless there is a specific rea-

\footnotetext{
*Correspondence: turkoglu@istanbul.edu.tr

1 Department of Clinical Microbiology, Anadolu Medical Center, Kocaeli 41400, Turkey

Full list of author information is available at the end of the article
}

son such as prolonged diarrhea or a history of travel to an endemic region. Although several case reports indicate the presence of Cyclospora cayetanensis disease in different regions of Turkey, epidemiological data on this pathogen are lacking [10-12]. In our microbiology laboratory in a 209 beds new hospital in Istanbul, we included Cyclospora testing in our routine algorithm for diarrheal disease diagnostics. We monitored the incidence Cyclospora for four consecutive seasons which peaked in the summer of 2007. In analyzing the cases, we found a high occurrence of cyclosporiasis which could be related to the unusual climatic conditions that occurred during 2007.

A total of 1876 patients (31\% pediatric, 69\% adult) with diarrhea were admitted to the Anadolu Medical Center outpatient clinics during June, July, and August of 2006, 2007, 2008, and 2009.

Stools were routinely investigated for coccidian parasites in the microbiology laboratory in the summer months. Direct wet mount examination was followed by formalin-acetate concentration (Para Pak, Meridian Diagnostics), Kinyoun's modified acid-fast stain. The oocysts were mostly diagnosed during a wet mount microscopic examination. Further or definitive diagnosis was made using stained smears. Characteristic oocysts appeared as spherical structures of $8-10 \mu \mathrm{m}$ in diameter, with variable acid-fast staining: some stain dark red or pink, and some remain unstained. As a standard test, 
autofluorescence under ultraviolet (UV) fluorescence illumination was also used for the diagnosis of Cyclospora infection in stool samples.

Samples found to be Cyclospora-positive upon microscopic examination were subjected to DNA extraction. Briefly, $100 \mu \mathrm{L}$ of stool suspension was vortexed vigorously with acid washed glass beads (SIGMA Glass beads, 425-600 $\mu \mathrm{m}$ ) for 10 minutes in the lysis buffer provided in the DNeasy Blood \& Tissue Kit (QIAGEN Inc. California), and DNA was purified according to the manufacturer's instructions. A single-step polymerase chain reaction (PCR) with Cyclospora-specific primers from the ITS-1 (first internal transcribed spacer) region of the Cyclospora genome (Ccits37f-GCTTGCTATGTTTTAGCATGTGG and Ccits501r-GCACAATGAATGCACA$C A C A$ ) was performed using $10 \mu \mathrm{L}$ of purified DNA [13].

A total of 17 cases of cyclosporiasis were detected among 505 stool samples from patients with diarrhea in 2007, and 14 samples were positive for C. cayetanensis by PCR (Figure 1). Only 2 cases were detected in 506 stool samples from patients with diarrhea (with both microscopic examination and PCR) in 2006, no cases were detected in 465 samples in 2008, and one case were detected in 400 stool samples over the same period in 2009. The majority of the cases were detected in a 15-day time period in 2007.

Stool cultures for Salmonella and Shigella, Aeromonas species, and Rotavirus and Adenovirus antigens gave negative results in these Cyclospora-positive samples. Fifty stool samples belonging to 2006-2009 from asymptomatic persons were screened for Cyclospora oocysts and found to be negative.

Diarrhea was persistent in most of our patients, with half of them also presenting with fever in 2007. All of the patients were successfully treated with trimethoprim-sulfamethoxazole (TMP/SMZ 160/800 mg/bid). After 7-10

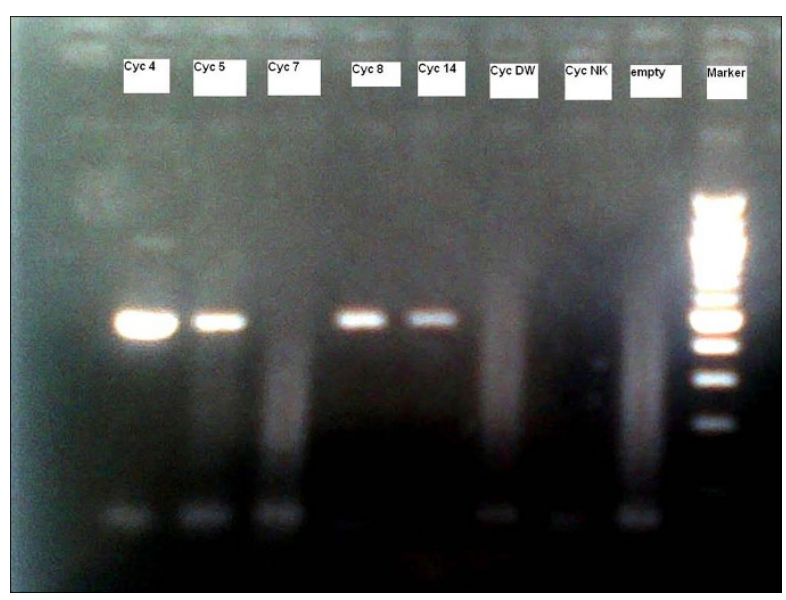

Figure 1 Agarose gel electrophoresis showing Cyclospora PCR results. Positive $=456 \mathrm{bp}$ band days, all patients were negative for Cyclospora oocysts upon stool examination.

According to patient records, 41\% (7/17) of the cases reported were connected with additional cases, including colleagues and family members who described similar symptoms. We believe that the total number of patients affected by Cyclospora infection was higher than the 17 cases reported. All of the patients were from a high socioeconomic background, and had a good sanitary condition. The number of patients admitted to the outpatient clinics of the hospital is about 3,500 per month, and the total number of diarrhea cases in the $6^{\text {th }}, 7$ and $8^{\text {th }}$ months is about 500 to 600 . There was no evident elevation in the total number of diarrhea cases in the month of July in the summer of 2007. How did a number of people of relatively high socioeconomic status surprisingly contract this pathogen over a very limited time period?

There have only been a limited number of cases of cyclosporiasis detected in Turkey thus far, and these were mainly imported cases from the warmer southern parts of the country and in poorer cities or villages with inferior infrastructure [10-12]. Studies of the prevalence of Cyclospora cayetanensis are limited, and as in other similar parts of the world the lack of epidemiological data is primarily due to unsatisfactory worldwide performance in the detection of a divergent multitude of diarrheal pathogens. The diagnostic algorithms are out-of-date, and do not include this pathogen. There are no positive data on Cyclospora cases in the Ministry of Health of Turkey records for 2007. Taking the Cyclospora prevalence from 2006 to 2009 as a baseline (there is no country-wide baseline level of endemicity), is the high prevalence in 2007 worth addressing?

There are some observations that could explain this increased prevalence in 2007.

1) There was no snowfall in the previous winter, which is not normal, in addition to the very high overall temperature in the summer months. 2) Importantly, the water levels of Istanbul drinking water reservoirs during 2007 were nearly empty, and water usage was very limited, which have resulted in insufficient food washing for items such as fruits and vegetables, especially those that cannot be peeled (e.g., lettuce and raspberries). 3) The city water is regularly screened for coccidia by the Istanbul Water and Sewerage Administration, and the results were negative from 2006-2009. 4) All of the Cyclospora-positive patients were admitted over a period of 15 days, and $88.2 \%(15 / 17)$ had a prolonged (7-15 days) history diarrhea. This finding coincides with previously reported cases from Turkey in terms of the seasonal emergence, and suggests a possible common source other than the water supply systems of the city. A highly probable source could be insufficiently washed food, especially green salads. The patient histories revealed a high percentage of 
green salad consumption $(16 / 17 ; 94 \%)$ in different restaurants, but no food or beverages were available for testing when the investigation occurred. The mean age of the patients was $41.94 \pm 9.99$ (range: 28 and 59). There were no Cyclospora infections detected in children. This strengthens the green salad hypothesis as this is not a favorite food of children.

PCR testing confirmed our diagnoses but is of limited value for routine diagnosis. The single-step PCR used here was not as sensitive as the conventional method and false negative PCR results might be due to inherent inhibitors, but is an initial step to further analyze the genome, and epidemiology of the parasite. Further investigations and reliable genomic fragments will be required to overcome the problems we encountered and to obtain data on the epidemiology of Cyclospora cayetanensis.

We could assume that perhaps a small outbreak occurred from an unknown source. There was clearly a waterless summer [14], and perhaps insufficient food washing as a result, but there remain some questions that need to be answered. Is Cyclospora cayetanensis an endemic pathogen in Istanbul that is found easily in the soil? Do changing climate conditions favor its sporulation?

In conclusion, Istanbul has a very crowded population ( $15 \%$ of Turkey, living in suburbs) similar to other important cities around the world, and must be surveyed closely. Our data on Cyclospora showed an unusual rise in the number of cases over a limited time period during a particular season, which must be considered. Notably, the cases were geographically separate and not clustered in a particular area.

There are other emerging infections such as CrimeanCongo hemorrhagic fever infections imported from countries where they are endemic that are finding new epidemiological niches (e.g. in central Turkey). Additional infections may be finding their niches due to the climate conditions described here.

Competing interests

The authors declare that they have no competing interests.

\section{Authors' contributions}

$\mathrm{MO}$ and ST contributed equally to this work; MO processed the samples and performed the majority of experiments; EH treated the patients, collected and provided patients data; ST designed the study and wrote the manuscript.

\section{Acknowledgements}

We thank Muazzez Celiloglu and Derya Gurkan for their technical assistance.

\section{Author Details}

${ }^{1}$ Department of Clinical Microbiology, Anadolu Medical Center, Kocaeli 41400 Turkey, 2Department of Infectious Diseases, Anadolu Medical Center, Kocaeli 41400, Turkey and 3Department of Microbiology and Clinical Microbiology, University of Istanbul, Istanbul Medical Faculty, 34093, Capa, Istanbul, Turkey

Received: 3 April 2010 Accepted: 23 April 2010 Published: 23 April 2010
References

1. Ortega YR, Gilman RH, Sterling CR: A new coccidian parasite (Apicomplexa: Eimeriidae) from humans. J Parasitol 1994, 80:625-629.

2. Herwaldt BL: Cyclospora cayetanensis: a review, focusing on the outbreaks of cyclosporiasis in the 1990s. Clin Infect Dis 2000, 31:1040-1057

3. Ortega YR, Sanchez R: Update on Cyclospora cayetanensis, a Food-Borne and Waterborne Parasite. Clin Microbiol Rev 2010, 23:218-234.

4. Centers for Disease Control \& Prevention Update: Outbreaks of Cyclospora cayetanensis infection United States and Canada, 1996. Morb Mortal Wkly Rep 1996, 45:611-612.

5. Gascon J, Corachan M, Bombi JA, Valls ME, Bordes JM: Cyclospora in patients with traveler's diarrhea. Scand J Infect Dis 1995, 27:511-514.

6. Herwaldt BL, Ackers ML: An outbreak in 1996 of cyclosporiasis associated with imported raspberries. The Cyclospora Working Group. NEngl J Med 1997, 336:1548-1556.

7. Ho AY, Lopez AS, Eberhart MG, Levenson R, Finkel BS, da Silva AJ, Roberts JM, Orlandi PA, Johnson CC, Herwaldt BL: Outbreak of cyclosporiasis associated with imported raspberries, Philadelphia, Pennsylvania. Emerg Infect Dis 2002, 8:783-788.

8. Huang P, Weber JT, Sosin DM, Griffin PM, Long EG, Murphy JJ, Kocka F, Peters C, Kallick C: The first reported outbreak of diarrheal illness associated with Cyclospora in the United States. Ann Intern Med 1995, 123:409-414.

9. Petry F, Hofstatter J, Schulz BK, Deitrich G, Jung M, Schirmacher P: Cyclospora cayetanensis: first imported infections in Germany. Infection 1997, 25:167-170.

10. Sancak B, Akyon Y, Erguven S: Cyclospora infection in five immunocompetent patients in a Turkish university hospital. J Med Microbiol 2006, 55:459-462.

11. Turk M, Turker M, Ak M, Karaayak B, Kaya T: Cyclosporiasis associated with diarrhea in an immunocompetent patient in Turkey. J Med Microbio 2004, 53:255-257.

12. Yazar S, Yalcin S, Sahin I: Human cyclosporiasis in Turkey. World J Gastroenterol 2004, 10:1844-1847.

13. Olivier C, Pas S van de, Lepp PW, Yoder K, Relman DA: Sequence variability in the first internal transcribed spacer region within and among cyclospora species is consistent with polyparasitism. Int J Parasitol 2001, 31:1475-1487

14. Istanbul Water And Sewerage Administration (ISKI) Database [http:// www.iski.gov.tr/Web/statik.aspx?KID=1000717]

doi: 10.1186/1756-3305-3-39

Cite this article as: Ozdamar et al., High occurrence of cyclosporiasis in Istanbul, Turkey, during a dry and warm summer Parasites \& Vectors 2010, 3:39

\section{Submit your next manuscript to BioMed Centra and take full advantage of:}

- Convenient online submission

- Thorough peer review

- No space constraints or color figure charges

- Immediate publication on acceptance

- Inclusion in PubMed, CAS, Scopus and Google Scholar

- Research which is freely available for redistribution 